\title{
Anchoring tri(8-quinolinolato)iron onto SBA-15 for partial oxidation of benzyl alcohol using water as the solvent
}

\author{
Xiaoyuan Yang, Jing Liu, Qiubin Kan, Jingqi Guan* \\ Jilin University, Key Laboratory of Surface and Interface Chemistry of Jilin Province, College of Chemistry, Changchun, \\ 130023, PR China \\ *Corresponding author: e-mail: guanjq@jlu.edu.cn
}

\begin{abstract}
Tri(8-quinolinolato)iron complex immobilized onto SBA-15 catalyst has been synthesized through a stepwise procedure. The characterization results indicated that the BET surface area, total pore volume and average pore width decrease after stepwise modification of SBA-15, while the structure keeps intact. Catalytic tests showed that $\mathrm{FeQ}_{3}$-SBA-15 catalyzes the oxidation reaction well with $34.8 \%$ conversion of benzyl alcohol and $74.7 \%$ selectivity to benzaldehyde when water is used as the solvent after $1 \mathrm{~h}$ reaction. In addition, homogeneous catalyst tri(8-quinolinolato)iron exhibits very bad catalytic behavior using water as the solvent.
\end{abstract}

Keywords: SBA-15, 8-quinolinol, iron, benzyl alcohol, benzaldehyde.

\section{INTRODUCTION}

Benzaldehyde is a very important organic intermediate in the industry of perfumery, pharmaceutical, dyestuff and agrochemicals which is produced by many reactions such as hydrolysis of benzyl chloride and oxidation of toluene ${ }^{1}$. The traditional catalytic processes inevitably lead to the generation of a large amount of undesired products such as organic chlorine or benzoic acid. Therefore, selective oxidation of alcohols to aldehydes using water as the solvent is an attractive and eco-friendly reaction route in the synthesis of fine chemicals and intermediates ${ }^{2}$.

Until now, many efforts have been devoted to the metal-catalyzed alcohol oxidations by using transition metals such as titanium ${ }^{3}$, vanadium ${ }^{4}$, chromium $^{5}$, manganese $^{6}$, iron $^{7}$, cobalt $^{8}$, nickel $^{9}$, copper ${ }^{10}$, silver $^{11}$, gold $^{12}$, ruthenium $^{13}$, palladium ${ }^{14}$, bimetallic ruthenium-copper ${ }^{15}$, palladium-gold ${ }^{16}$, and manganese-gold ${ }^{17}$. Especially very recently, abundant investigations have been focused on the usage of noble metals for the transformation of benzyl alcohol to benzaldehyde ${ }^{18-22}$, while few efforts have been devoted to the catalytic application of the cheap metal iron for this reaction? ${ }^{7}$.

Compared with metal oxides such as $\mathrm{TiO}_{2}, \mathrm{Al}_{2} \mathrm{O}_{3}$ and $\mathrm{CeO}_{2}$, mesoporous silicate SBA-15 exhibit specific physical and chemical properties (such as large BET surface area, regular pore structure, large pore size, tunable surface chemistry) and therefore has been used widely as supports in various organic catalytic reaction ${ }^{23-30}$. The surface chemistry of SBA-15 is a key factor to the catalytic performance. Generally, the SBA- 15 material exhibits large amounts of surface silicon hydroxyl, which could be modified and incorporated active sites to efficiently catalyze the target reaction.

In the current work, tri(8-quinolinolato)iron complexes was chelated onto aminopropyl-functionalized SBA-15 for the selective oxidation of benzyl alcohol to benzaldehyde. The effects of parameters, including the types of solvent, the reaction temperature, the reaction time, the amount of $\mathrm{H}_{2} \mathrm{O}_{2}$, and the recyclability of the catalyst have been investigated in detail.

\section{EXPERIMENTAL}

\section{Catalyst Preparation}

SBA-15 was synthesized according to the literature $^{31}$. In a typical synthesis, $2 \mathrm{~g}$ of Pluronic P123 [(EO)20(PO)70(EO)20, Aldrich] was dissolved in 15 $\mathrm{mL}$ of $\mathrm{H}_{2} \mathrm{O}$ and $60 \mathrm{~mL}$ of $2 \mathrm{M} \mathrm{HCl}$, and then $4.68 \mathrm{~mL}$ $(0.02 \mathrm{~mol})$ of TEOS was added under stirring at $40^{\circ} \mathrm{C}$. The molar composition of the mixture was TEOS: 0.017P123: $6 \mathrm{HCl}: 192 \mathrm{H}_{2} \mathrm{O}$. Afterwards, the resultant mixture was maintained under stirring at $40^{\circ} \mathrm{C}$ for $24 \mathrm{~h}$, followed by aging under static condition at $100^{\circ} \mathrm{C}$ for $24 \mathrm{~h}$. Finally, the solid product was recovered by filtration and washed with distilled water. After air-dried at ambient temperature overnight, it was calcined at $550^{\circ} \mathrm{C}$ for $8 \mathrm{~h}$ to remove the template. The obtained sample was denoted as SBA-15.

Aminopropyl-functionalized SBA-15 material APS-SBA-15 was synthesized by post synthetic grafting method (Fig. 1). SBA-15 was first dried under vacuum at $100^{\circ} \mathrm{C}$ for $5 \mathrm{~h}$. Then $0.5 \mathrm{~g}$ of dried SBA- 15 was refluxed in dried toluene with $0.1 \mathrm{~mL}(0.4 \mathrm{mmol})$ APTES (3-aminopropyltriethoxysilane) for $10 \mathrm{~h}$. Then the solid was filtered and washed abundantly with several solvents with different polarity $\left(\mathrm{CH}_{2} \mathrm{Cl}_{2}\right.$, hexane and ethanol) to remove the remaining unsupported APTES. The pale solid was dried overnight. The obtained samples were denoted as APS-SBA-15.

$\operatorname{Tri}(8$-quinolinolato)iron was synthesized as follows. In a typical synthesis, $15 \mathrm{mmol}$ of 8-quinolinol ligand was dissolved in $20 \mathrm{~mL}$ THF, followed by the dropwise addition of a solution of $5 \mathrm{mmol} \mathrm{FeCl}{ }_{3} \cdot 6 \mathrm{H}_{2} \mathrm{O}$ in 10 $\mathrm{mL}$ THF at reflux temperature. The resultant solution was stirred and refluxed for $2 \mathrm{~h}$. After cooling, the solid product was separated by filtration and denoted as $\mathrm{FeQ}_{3}$.

$\mathrm{FeQ}_{3}$-SBA-15 was prepared by dissolving $\mathrm{FeQ}_{3}(0.2$ mmol) in $10 \mathrm{ml} \mathrm{CHCl}$ and by stirring the above APSSBA-15 $(0.1 \mathrm{~g})$ in suspension under reflux conditions for $12 \mathrm{~h}$. The yellow solid thus formed during stirring was filtered, washed with methanol using Soxhlet and dried under vacuum (Fig. 1).

For comparison, Fe-SBA-15 was prepared through impregnating 3.0 wt. $\% \mathrm{Fe}\left(\mathrm{NO}_{3}\right)_{3} \cdot 9 \mathrm{H}_{2} \mathrm{O}$ on SBA-15 and then drying and calcining at $500^{\circ} \mathrm{C}$ for $4 \mathrm{~h}$. 


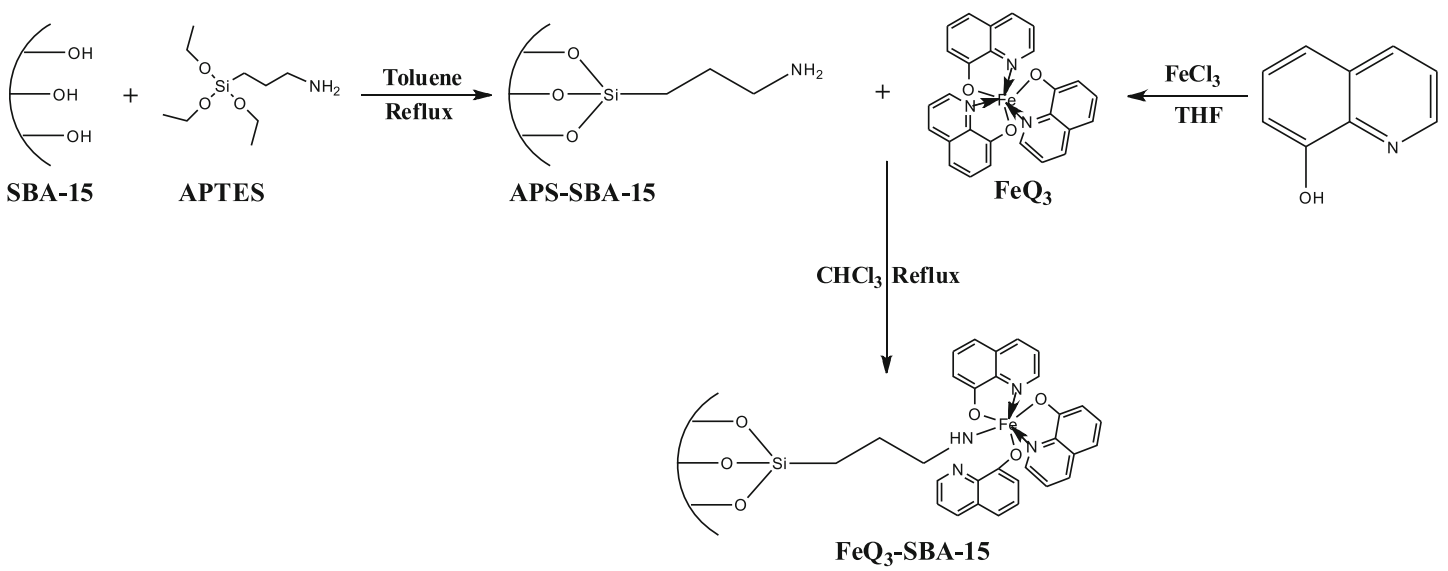

Figure 1. Synthetic route for $\mathrm{FeQ}_{3}-\mathrm{SBA}-15$

\section{Catalyst Characterization}

Powder X-ray diffraction patterns (XRD) were obtained on a Rigaku D/max-2200 (0.2॰/min) using $\mathrm{Cu}$ $\mathrm{Ka}$ radiation $\left(40 \mathrm{kV}, 40 \mathrm{~mA}\right.$ ). $\mathrm{N}_{2}$ adsorption-desorption isotherms were measured with a Micromeritics ASAP 2010 system at liquid $\mathrm{N}_{2}$ temperature. Before measurements, the sample was outgassed at $130^{\circ} \mathrm{C}$ for $6 \mathrm{~h}$. The BET surface area was calculated using the Brunauer-Emmett-Teller (BET) method. SEM photographs were taken on a FESEM XL-30 field emission scanning electron microscope. Infrared spectra (IR) of samples were recorded in $\mathrm{KBr}$ disks using a NICOLET impact 410 spectrometer. Metal content was estimated by inductively coupled plasma atomic emission spectroscopy (ICP-AES) analysis conducted on a Perkin-Elmer emission spectrometer. Elemental analyses of nitrogen were obtained with a VarioEL CHN elemental analyzer.

\section{Catalytic Tests}

The catalyst $(0.05 \mathrm{~g})$, benzyl alcohol $(3 \mathrm{~mL}), 35 \% \mathrm{H}_{2} \mathrm{O}_{2}$ (4 mL) and solvent (water, acetone or acetonitrile) (10 $\mathrm{mL}$ ) were placed into a reaction vessel. The resulting mixture was vigorously stirred at $80^{\circ} \mathrm{C}$ under nitrogen. After certain times, the catalysts were separated by filtration. The products were analyzed with a gas chromatography (Shimadzu, GC-8A) equipped with a XE60 capillary column and FID detector.

\section{RESULTS AND DISCUSSION}

The powder XRD patterns of the synthesized SBA-15, APS-SBA-15 and $\mathrm{FeQ}_{3}$-SBA-15 are shown in Figure 2. For all of the samples, three well-resolved peaks can be clearly observed, indicating that the prepared materials contain well-ordered hexagonal arrays of one dimensional channel structure ${ }^{\mathbf{3 1}}$. However, the decrease in the intensity of the (110) and (200) peaks for $\mathrm{FeQ}_{3}-\mathrm{SBA}-15$ is observed, suggesting the formation of less ordered mesostructure. In addition, the slight shift of the diffraction peaks of the materials after the introduction of APS and $\mathrm{FeQ}_{3}$ toward larger $2 \theta$ angles indicates a slight shrinkage of the cell dimension.

$\mathrm{N}_{2}$ adsorption-desorption isotherms and pore size distributions of SBA-15, APS-SBA-15 and FeQ ${ }_{3}$-SBA-15 are depicted in Figure 3. These isotherms are classified as type IV, with a sharp capillary condensation step at high relative pressure and $\mathrm{H} 1$ hysteresis loop, which reveals the presence of large channel-like pores in

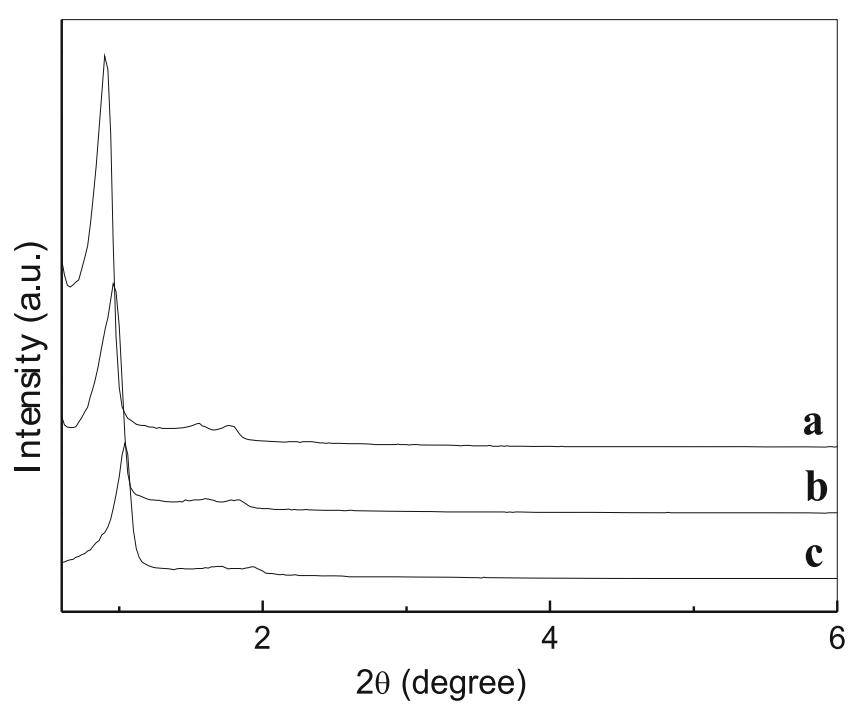

Figure 2. XRD patterns of (a) SBA-15, (b) APS-SBA-15, and (c) $\mathrm{FeQ}_{3}-\mathrm{SBA}-15$

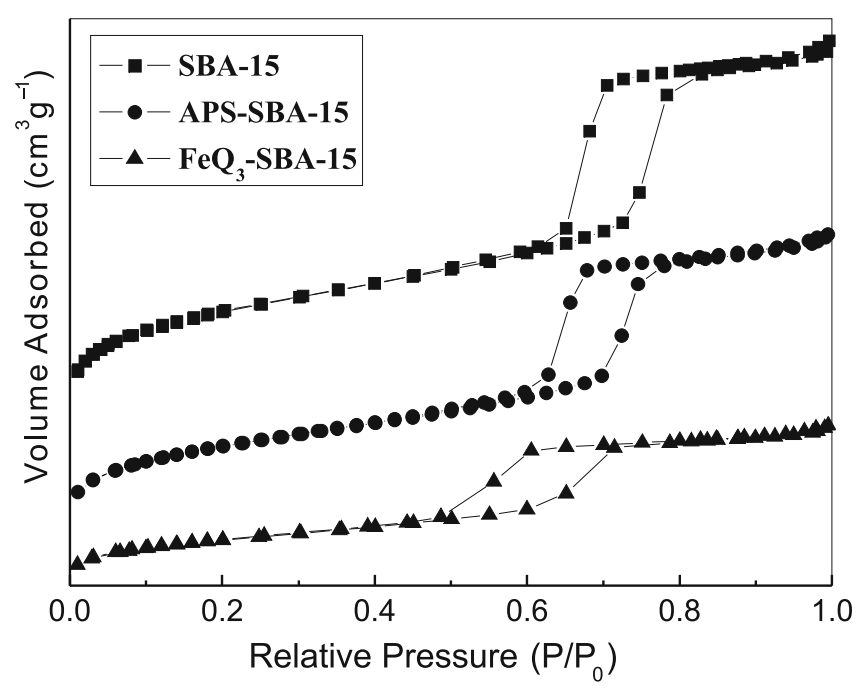

Figure 3. $\mathrm{N}_{2}$ adsorption/desorption isotherms of (a) SBA-15, (b) APS-SBA-15 and (c) $\mathrm{FeQ}_{3}$-SBA-15

a narrow range of size ${ }^{32}$. The BET surface area, pore volume and pore diameter of SBA-15, APS-SBA-15 and $\mathrm{FeQ}_{3}-\mathrm{SBA}-15$ are presented in Table 1 . The BET surface, the total pore volume area and the average pore width significantly decrease after functionalization of $\mathrm{FeQ}_{3}$ onto APS-SBA-15.

FT-IR spectra of SBA-15, APS-SBA-15 and $\mathrm{FeQ}_{3-}$ -SBA-15 are presented in Figure 4. In all case, the typical Si-O-Si bands are observed nearly at 1080 , 
Table 1. Structural and textural parameters of the synthesized materials

\begin{tabular}{|c|c|c|c|}
\hline Sample & $\mathrm{S}_{\mathrm{BET}}{ }^{\mathrm{a}}\left[\mathrm{m}^{2} \mathrm{~g}^{-1}\right]$ & $\mathrm{D}_{\mathrm{p}}^{\mathrm{b}}[\mathrm{nm}]$ & $V_{p}^{c}\left[\mathrm{~cm}^{3} \mathrm{~g}^{-1}\right]$ \\
\hline SBA-15 & 892 & 8.9 & 1.30 \\
\hline APS-SBA-15 & 697 & 8.0 & 0.96 \\
\hline $\mathrm{FeQ}_{3}-\mathrm{SBA}-15$ & 165 & 4.5 & 0.29 \\
\hline
\end{tabular}

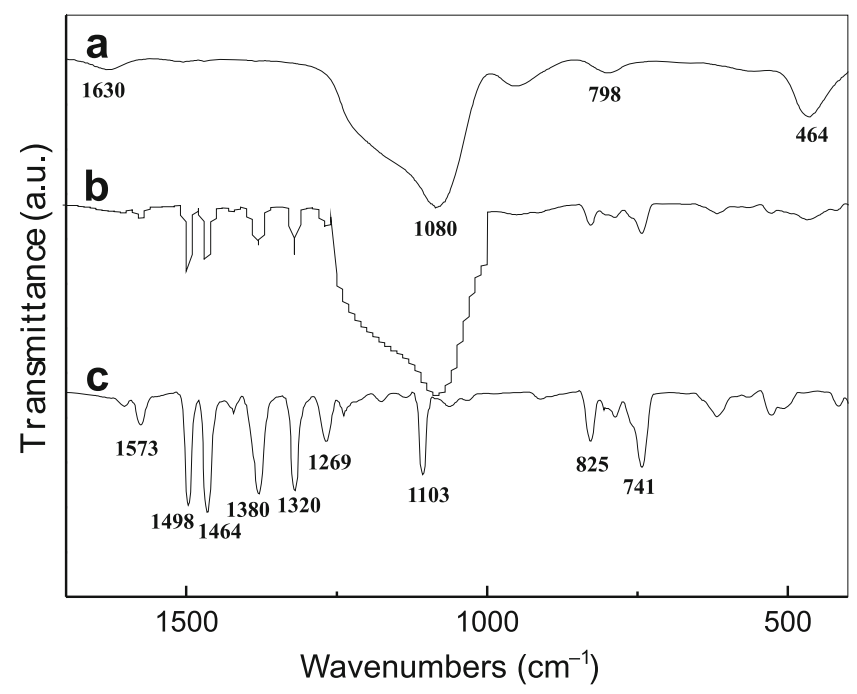

Figure 4. FT-IR spectra of (a) APS-SBA-15, (b) FeQ3-SBA-15 and (c) $\mathrm{FeQ}_{3}$

$798,464 \mathrm{~cm}^{-1}$ due to the formation of SBA-15 silica framework ${ }^{33}$. The bands around $1630 \mathrm{~cm}^{-1}$ are mainly aroused by the bend vibration of $\mathrm{O}-\mathrm{H}$ and physically adsorbed water molecular. After functionalization of SBA-15, the prominent bands at 741, 825, 1103, $1269,1320,1380,1464,1498$ and $1573 \mathrm{~cm}^{-1}$ in the spectrum of $\mathrm{FeQ}_{3}$-SBA-15 (Fig. 4b) are assigned to $\mathrm{C}-\mathrm{O}, \mathrm{C}-\mathrm{N}$ and aromatic ring vibrations of ligands ${ }^{33}$, suggesting that $\mathrm{FeQ}_{3}$ has been successfully grafted onto APS-SBA-15.

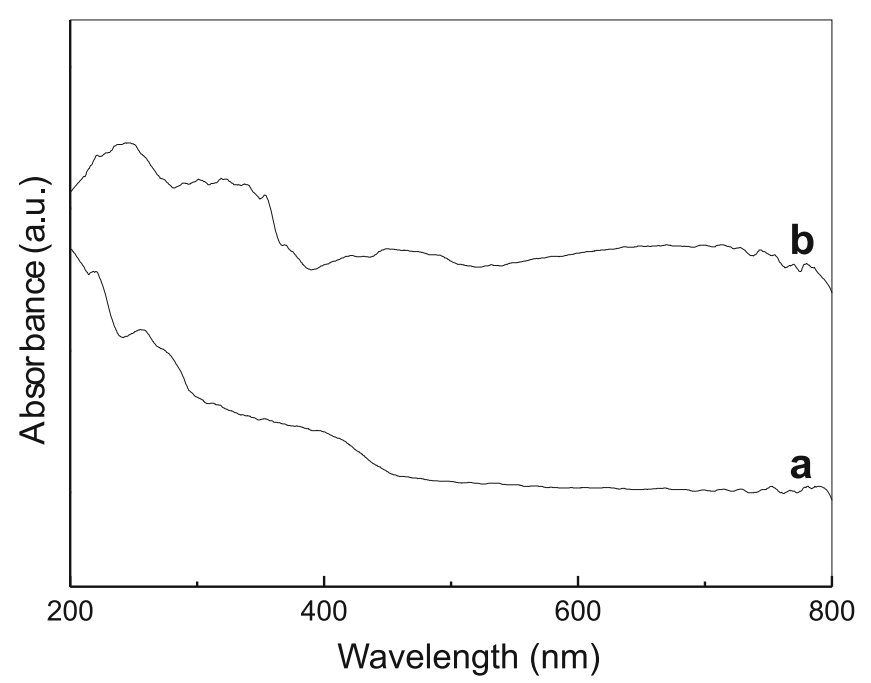

Figure 5. UV-vis spectra of (a) SBA-15 and (b) $\mathrm{FeQ}_{3}-\mathrm{SBA}-15$
Figure 5 exhibits UV-vis spectra of SBA-15 and $\mathrm{FeQ}_{3}$-SBA-15. Compared with SBA-15, the absorption bands in the range of $200-400 \mathrm{~nm}$ are observed in the tethered catalyst $\mathrm{FeQ}_{3}-\mathrm{SBA}-15$, which are assigned to $n-\pi^{*}, \pi-\pi^{*}$ ligand charge transfer ${ }^{33}$, suggesting that the bis(8-quinolinolato)iron (III) has been chelated with APS-SBA-15. The d-d transitions at ca. $460 \mathrm{~nm}$ are observed for $\mathrm{FeQ}_{3}$-SBA-15, indicating that tri(8-quinolinolato)iron complexes have been incorporated onto the surface of SBA-15.

Quantification of the functional group loaded in SBA-15 was performed for the materials using elemental analysis (CHN) and ICP-AES analysis (Table 2). The results show that molar ratio of $\mathrm{N} / \mathrm{Fe}$ is close to $4 / 1$, which indicating a $\mathrm{Fe}^{3+}$ ion chelating one APTES molecule and three 8-quinolinol molecules as shown in Figure 1.

The catalytic performance of $\mathrm{FeQ}_{3}$-SBA-15 was carried out in the selective oxidation of benzyl alcohol with $\mathrm{H}_{2} \mathrm{O}_{2}$ as oxidant. For comparison, the catalytic performances of homogeneous catalysts $\mathrm{FeCl}_{3}$ and $\mathrm{FeQ}_{3}$, and heterogeneous supported catalyst Fe-SBA-15 were also investigated and the reaction data are listed in Table 3. It is obvious that the oxidation reaction cannot be carried out without catalysts. In addition, the catalytic behavior of $\mathrm{FeCl}_{3}$ is the worst, over which only $5.5 \%$ conversion can be achieved. Moreover, the catalytic behaviors of homogeneous catalyst $\mathrm{Fe}_{3}$ and supported catalyst Fe-SBA-15 are worse than that of $\mathrm{FeQ}_{3}-\mathrm{SBA}-15$ under our test conditions.

In order to get the optimal reaction conditions, different parameters such as reaction media, oxidant amount, reaction time and temperature were investigated. The influence of reaction media on the catalytic performance was performed by using different solvents (water, acetone, and acetonitrile) and the results are showed in Table 4. It is interesting to note that $\mathrm{FeQ}_{3}$-SBA-15 catalyzes the oxidation reaction well when water is used as the solvent, followed by acetone, while only $17.4 \%$ conversion can be obtained when acetonitrile is used as the solvent.

The temperature has great influence on the catalytic performance. As shown in Table 4, low temperature causes very low benzyl alcohol conversion. For example, only $23.7 \%$ of benzyl alcohol conversion can be achieved at $60^{\circ} \mathrm{C}$. Increasing reaction temperature could synchronously raise the catalytic activity. However, too high reaction temperature might cause deep oxidation and thus increase the selectivity to benzoic acid.

The reaction time has some influence on the catalytic behavior. As can be seen from Table 4, the benzyl alcohol conversion gradually increased from 30 to $35.9 \%$, while the selectivity to benzaldehyde decreases step by step from 80.6 to $70.7 \%$ by prolonging the reaction from 0.5 to $2 \mathrm{~h}$, while further prolonging reaction time would result in the decrease of benzaldehyde selectivity.

From the results of effect of different $\mathrm{H}_{2} \mathrm{O}_{2}$ amount on the benzyl alcohol oxidation in Table 4, it can be seen that the conversion of benzyl alcohol remarkably

Table 2. Elementary analysis and ICP-AES analysis results of APS-SBA-15 and FeQ3-SBA-15

\begin{tabular}{|l|c|c|c|c|}
\hline Sample & $\mathrm{C}$ & $\mathrm{H}$ & $\mathrm{N}$ & $\mathrm{Fe}$ \\
\hline APS-SBA-15 & $2.86(3.34)$ & $0.86(12.04)$ & $1.0(1)$ & - \\
\hline FeQ ${ }_{3}$-SBA-15 & $6.42(7.57)$ & $0.45(6.36)$ & $0.99(1)$ & $0.50(0.27)$ \\
\hline
\end{tabular}

${ }^{\mathrm{a}}$ The values in the brackets represent the molar ratio of $\mathrm{C}, \mathrm{H}, \mathrm{N}$ and $\mathrm{Cu}$. 
Table 3. Catalytic data of the benzyl alcohol oxidation over different catalysts ${ }^{\mathrm{a}}$

\begin{tabular}{|l|c|c|c|}
\hline \multirow{2}{*}{ Catalyst } & Conversion & \multicolumn{2}{|c|}{ Selectivity [\%] } \\
\cline { 3 - 4 } & {$[\%]$} & Benzaldehyde & Benzoic acid \\
\hline No catalyst & trace & - & - \\
\hline $\mathrm{FeCl}_{3}$ & 5.5 & 50.3 & 49.7 \\
\hline $\mathrm{FeQ}_{3}$ & 25.6 & 60.9 & 39.1 \\
\hline $\mathrm{Fe}_{3} \mathrm{SBA}-15$ & 29.8 & 70.8 & 29.2 \\
\hline $\mathrm{FeQ}_{3}$-SBA-15 & 34.8 & 74.7 & 25.3 \\
\hline
\end{tabular}

${ }^{a}$ Reaction conditions: catalyst $(0.05 \mathrm{~g})$, benzyl alcohol $(3 \mathrm{~mL}), \mathrm{H}_{2} \mathrm{O}_{2}$ $(4 \mathrm{~mL}), \mathrm{H}_{2} \mathrm{O}(10 \mathrm{~mL})$, reaction time $(1 \mathrm{~h})$, and reaction temperature $\left(80^{\circ} \mathrm{C}\right)$.

improves from 16.9 to $34.8 \%$ after $6 \mathrm{~h}$ by increasing the $\mathrm{H}_{2} \mathrm{O}_{2}$ amount from 2 to $4 \mathrm{ml}$. It is also found that further raising $\mathrm{H}_{2} \mathrm{O}_{2}$ amount has relatively little influence on the conversion but results in the reduction of the selectivity to benzaldehyde.

Much research has found that homogeneous catalysts showed high catalytic performance in organic solvent, while few work focused on using water as the solvent. Actually, according to our results in Table 3, the homogeneous catalyst $\mathrm{FeQ}_{3}$ shows worse catalytic behavior in water than the heterogeneous one. This might be due to the worse solubility in water than in organic solvent. For example, Mahdavi et al investigated the effect of solvents on the oxidation of benzyl alcohol with TBHP in the presence of $[\mathrm{Mn} \text { (bipy)2 }]^{2+} / \mathrm{HMS}$ and found that the best conversion (40.2\%) was achieved in an aprotic solvent acetonitrile, while the worst conversion (only
$7.6 \%$ ) was obtained in a protic solvent ethanol after $8 \mathrm{~h}$ reaction ${ }^{34}$. In our catalytic system, the efficient synergistic effect between $\mathrm{FeQ}_{3}$ complexes and the SBA-15 support is one of the reasons for the better catalytic performance $\mathrm{FeQ}_{3}$-SBA-15 with water as solvent.

The recyclability and stability of $\mathrm{FeQ}_{3}$-SBA- 15 for benzyl alcohol oxidation with $\mathrm{H}_{2} \mathrm{O}_{2}$ as oxidant and water as solvent were investigated (Fig. 6). The solid catalyst was easily recovered by filtration after each reaction cycle, washed thoroughly with acetone and water, dried in the vacuum at $60^{\circ} \mathrm{C}$ for $12 \mathrm{~h}$ and reused for the subsequent cycles. The reused catalyst exhibited a negligible decrease in the catalytic activity and selectivity in three consecutive runs.

Based on our experimental results and other related literatures ${ }^{1,2,5,7}$, a reasonable reaction mechanism for oxidation of benzyl alcohol with $\mathrm{H}_{2} \mathrm{O}_{2}$ over $\mathrm{FeQ}_{3}$-SBA-15 has been postulated in Scheme 1. Primarily the Fe Lewis acid sites react with $\mathrm{H}_{2} \mathrm{O}_{2}$ to form $\mathrm{Fe}$ peroxo complex and the complex further reacts with benzyl alcohol to give an intermediate which leads to benzaldehyde and regenerate the active sites. The formation of benzoic acid may be caused by deep oxidation of benzaldehyde.

\section{CONCLUSIONS}

Novel heterogeneous catalyst $\mathrm{FeQ}_{3}$-SBA-15 has been synthesized by chelating $\mathrm{FeQ}_{3}$ complexes onto aminopropyl-functionalized SBA-15. The characterization results

Table 4. Catalytic data of the benzyl alcohol oxidation over $\mathrm{FeQ}_{3}-\mathrm{SBA}-15^{\mathrm{a}}$

\begin{tabular}{|c|c|c|c|c|c|c|}
\hline & $\mathrm{H}_{2} \mathrm{O}_{2}$ & $\mathrm{~T}$ & Time & Conversion & \multicolumn{2}{|c|}{ Selectivity [\%] } \\
\hline & {$[\mathrm{ml}]$} & {$\left[{ }^{\circ} \mathrm{C}\right]$} & {$[\mathrm{h}]$} & {$[\%]$} & Benzaldehyde & Benzoic acid \\
\hline Water & 4 & 80 & 1 & 34.8 & 74.7 & 25.3 \\
\hline Acetone & 4 & 80 & 1 & 18.8 & 84.5 & 15.5 \\
\hline Water & 4 & 60 & 1 & 23.7 & 80.7 & 19.3 \\
\hline Water & 4 & 70 & 1 & 25.4 & 77.4 & 22.6 \\
\hline Water & 4 & 90 & 1 & 35.1 & 71.5 & 28.5 \\
\hline Water & 4 & 80 & 0.5 & 30.0 & 80.6 & 19.4 \\
\hline Water & 4 & 80 & 2 & 35.9 & 70.7 & 29.3 \\
\hline Water & 4 & 80 & 4 & 40.9 & 65.0 & 35.0 \\
\hline Water & 2 & 80 & 1 & 16.9 & 80.8 & 19.2 \\
\hline Water & 3 & 80 & 1 & 28.0 & 79.3 & 20.7 \\
\hline Water & 5 & 80 & 1 & 36.7 & 68.2 & 31.8 \\
\hline
\end{tabular}

${ }^{a}$ Reaction conditions: catalyst $(0.05 \mathrm{~g})$, benzyl alcohol $(3 \mathrm{~mL})$.

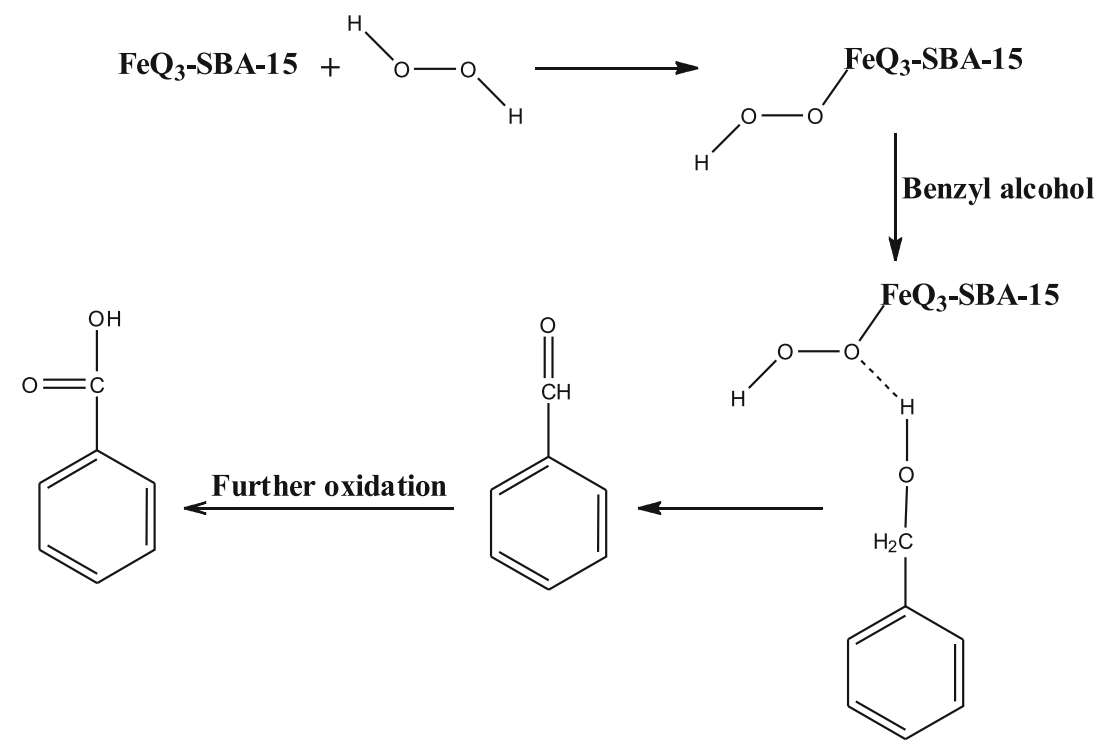

Scheme 1. The mechanism of the conversion of benzyl alcohol to benzaldehyde and benzoic acid over FeQ ${ }_{3}-\mathrm{SBA}_{-15}$ 


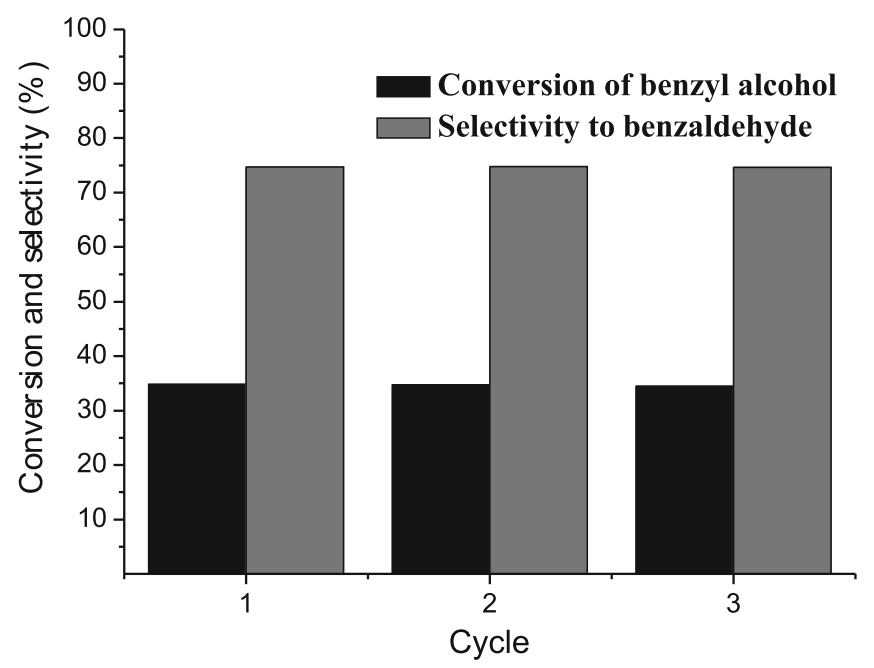

Figure 6. Reuse of $\mathrm{FeQ}_{3}$-SBA-15 for the selective oxidation of benzyl alcohol (Reaction conditions: catalyst $(0.05 \mathrm{~g})$, benzyl alcohol $(3 \mathrm{~mL}), \mathrm{H}_{2} \mathrm{O}_{2}(4 \mathrm{~mL}), \mathrm{H}_{2} \mathrm{O}(10 \mathrm{~mL})$, reaction time $(1 \mathrm{~h})$, and reaction temperature $\left.\left(80^{\circ} \mathrm{C}\right)\right)$

demonstrate that the pore structure of SBA-15 remain intact after multiple synthetic procedure. In addition, a detail research was carried out to optimize the reaction conditions of benzyl alcohol oxidation over $\mathrm{FeQ}_{3}-\mathrm{SBA}-15$. It is found that $\mathrm{FeQ}_{3}$-SBA-15 exhibits better catalytic performance with water as the solvent due to its unique pore structure of SBA-15 and efficient synergistic effect between $\mathrm{FeQ}_{3}$ and the SBA-15 support.

\section{ACKNOWLEDGMENT}

This work was supported by the National Natural Science Foundation of China (21303069), and Jilin province (201105006).

\section{LITERATURE CITED}

1. Prakash, S., Charan, C., Singh, A.K. \& Shahi, V.K. (2013). Mixed metal nanoparticles loaded catalytic polymer membrane for solvent free selective oxidation of benzyl alcohol to benzaldehyde in a reactor. Appl. Catal. B: Environ. 132, 62-69. DOI: 10.1016/j.apcatb.2012.11.001.

2. Yu, X., Huo, Y., Yang, J., Chang, S., Ma, Y. \& Huang, W. (2013). Reduced graphene oxide supported Au nanoparticles as an efficient catalyst for aerobic oxidation of benzyl alcohol. Appl. Surf. Sci. 280, 450-455. DOI: 10.1016/j.apsusc.2013.05.008.

3. Spasiano, D., Prieto Rodriguez, L.D.P., Carbajo Olleros, J., Malato, S., Marotta, R. \& Andreozzi, R. (2013). $\mathrm{TiO}_{2} / \mathrm{Cu}(\mathrm{II})$ photocatalytic production of benzaldehyde from benzyl alcohol in solar pilot plant reactor. Appl. Catal. B: Environ. 136, 56-63. DOI: 10.1016/j.apcatb.2013.01.055.

4. Pillai, U.R. \& Sahle-Demessie, E. (2004). Selective oxidation of alcohols over vanadium phosphorus oxide catalyst using hydrogen peroxide. Appl. Catal. B: Gen. 276(1-2), 139-144. DOI: 10.1016/j.apcata.2004.07.052.

5. Wang, X., Wu, G., Li, J., Zhao, N., Wei, W. \& Sun, Y. (2007). Surface-modified improvement in catalytic performance of $\mathrm{Cr}$ (salen) complexes immobilized on MCM-41 in solvent-free selective oxidation of benzyl alcohol. Catal. Lett. 119 (1-2), 87-94. DOI: 10.1007/s10562-007-9197-3.

6. Habibi, D. \& Faraji, A.R. (2013). Synthesis, characterization and application of a nano-manganese-catalyst as an efficient solid catalyst for solvent free selective oxidation of ethylbenzene, cyclohexene, and benzylalcohol. Appl. Surf. Sci. 276, 487-496. DOI: 10.1016/j.apsusc.2013.03.121.
7. Spasiano, D., Marotta, R., Di Somma, I., Andreozzi, R. \& Caprio, V. (2013). Fe(III)-photocatalytic partial oxidation of benzyl alcohol to benzaldehyde under UV-solar simulated radiation. Photochem. Photobiol. Sci. 12 (11), 1991-2000. DOI: 10.1039/c3pp50210d.

8. Pathan, S. \& Patel, A. (2013). Solvent free clean selective oxidation of alcohols catalyzed by mono transition metal (Co, $\mathrm{Mn}, \mathrm{Ni}$ )-substituted Keggin-phosphomolybdates using hydrogen peroxide. Appl. Catal. B: Gen. 459, 59-64. DOI: 10.1016/j. apcata.2013.03.044.

9. Zhao, G., Deng, M., Jiang, Y., Hu, H., Huang, J. \& Lu, Y. (2013). Microstructured $\mathrm{Au} / \mathrm{Ni}$-fiber catalyst: Galvanic reaction preparation and catalytic performance for low-temperature gas-phase alcohol oxidation. J. Catal. 301, 46-53. DOI: 10.1016/j. jcat.2013.01.020.

10. Shilpa, M.L. \& Gayathri, V. (2013). Liquid-phase catalytic oxidation of organic substrates by a recyclable polymer-supported copper(II) complex. Transit. Metal Chem. 38 (6), 705-713. DOI: 10.1007/s11243-013-9740-6.

11. Zhang, Q., Cai, S., Li, L., Chen, Y., Rong, H., Niu, Z. \& Li, Y. (2013). Direct Syntheses of Styryl Ethers from Benzyl Alcohols via Ag Nanoparticle-Catalyzed Tandem Aerobic Oxidation. ACS Catal. 3 (7), 1681-1684. DOI: 10.1021/cs400295h.

12. Sharma, P., Darabdhara, G., Reddy, T.M., Borah, A., Bezboruah, P., Gogoi, P. \& Das, M.R. (2013). Synthesis, characterization and catalytic application of Au NPs-reduced graphene oxide composites material: an eco-friendly approach. Catal. Commun. 40, 139-144. DOI: 10.1016/j.catcom.2013.06.021.

13. Sousa, S.C.A., Bernardo, J.R., Florindo, P.R. \& Fernandes, A.C. (2013). Efficient and selective oxidation of alcohols catalyzed by oxo-rhenium complexes. Catal. Commun. 40, 134-138. DOI: 10.1016/j.catcom.2013.06.012.

14. Al Badran, F., Awdry, S. \& Kolaczkowski, S.T. (2013). Development of a continuous flow reactor for pharmaceuticals using catalytic monoliths: $\mathrm{Pt} / \mathrm{C}$ selective oxidation of benzyl alcohol. Catal. Today 216, 229-239. DOI: 10.1016/j. cattod.2013.04.017.

15. Friedrich, H.B., Khan, F., Singh, N. \& van Staden, M. (2001). The Ru-Cu-Al-hydrotalcite-catalysed oxidation of alcohols to aldehydes or ketones. Synlett 2001 (6), 869-871. DOI: 10.1055/s-2001-14595.

16. Feng, J., Ma, C., Miedziak, P.J., Edwards, J.K., Brett, G.L., Li, D. \& Hutchings, G.J. (2013). Au-Pd nanoalloys supported on $\mathrm{Mg}-\mathrm{Al}$ mixed metal oxides as a multifunctional catalyst for solvent-free oxidation of benzyl alcohol. Dalton Trans. 42 (40), 14498-14508. DOI: 10.1039/c3dt51855h.

17. Mandal, S., Santra, C., Bando, K.K., James, O.O., Maity, S., Mehta, D. \& Chowdhury, B. (2013). Aerobic oxidation of benzyl alcohol over mesoporous Mn-doped ceria supported Au nanoparticle catalyst. J. Mol. Catal. A: Chem. 378, 47-56. DOI: 10.1016/j.molcata.2013.05.011.

18. Dong, J.J., Unjaroen, D., Mecozzi, F., Harvey, E.C., Saisaha, P., Pijper, D. \& Browne, W.R. (2013). Manganese-Catalyzed Selective Oxidation of Aliphatic C-H groups and Secondary Alcohols to Ketones with Hydrogen Peroxide. ChemSusChem 6 (9), 1774-1778. DOI: 10.1002/cssc.201300378.

19. Ravat, V., Nongwe, I., Meijboom, R., Bepete, G. \& Coville, N.J. (2013). Pd on boron-doped hollow carbon spheres - PdO particle size and support effects. J. Catal. 305 (0), 36-45. DOI: http://dx.DOI.org/10.1016/j.jcat.2013.04.018

20. Liu, C., Tang, S. \& Lei, A. (2013). Oxidant controlled Pd-catalysed selective oxidation of primary alcohols. Chem. Commun. 49 (13), 1324-1326. DOI: 10.1039/C2CC38086B.

21. Cui, W., Zhu, H., Jia, M., Ao, W., Zhang, Y. \& Zhaorigetu, B. (2013). One-pot synthesis of imines from benzyl alcohol and amines on $\mathrm{Au} / \mathrm{ZrO} 2$ catalyst. React. Kinet. Mech. Catal. 109 (2), 551-562. DOI: 10.1007/s11144-013-0576-z.

22. Liu, C., Tang, S. \& Lei, A. (2013). Oxidant controlled Pd-catalysed selective oxidation of primary alcohols. Chem. Commun. 49 (13), 1324-1326. DOI: 10.1039/c2cc38086b. 
23. Liu, B., Liu, H., Wang, C., Liu, L., Wu, S., Guan, J. \& Kan, Q. (2012). Exploration of acid-base geometric influence on cooperative activation for aldol reaction. Appl. Catal. A: Gen. 443, 1-7. DOI: 10.1016/j.apcata.2012.06.020.

24. Li, Z., Liu, L., Hu, J., Liu, H., Wu, S., Huo, Q. \& Kan, Q. (2012). Epoxidation of styrene with molecular oxygen catalyzed by a novel oxovanadium(IV) catalyst containing two different kinds of ligands. Appl. Organometal. Chem. 26 (5), 252-257. DOI: 10.1002/aoc.2861.

25. Rimoldi, M., Fodor, D., van Bokhoven, J.A. \& Mezzetti, A. (2013). A stable 16-electron iridium(iii) hydride complex grafted on SBA-15: a single-site catalyst for alkene hydrogenation. Chem. Commun. 49 (96), 11314-6. DOI: 10.1039/c3cc47296e.

26. Canilho, N., Jacoby, J., Pasc, A., Carteret, C., Dupire, F., Stebe, M.J. \& Blin, J.L. (2013). Isocyanate-mediated covalent immobilization of Mucor miehei lipase onto SBA-15 for transesterification reaction. Colloid Surface B 112, 139-45. DOI: 10.1016/j.colsurfb.2013.07.024.

27. Massah, A.R., Kalbasi, R.J. \& Kaviyani, S. (2013). Synthesis, characterization, and application of a manganese Schiff base complex containing salicylaldehyde-poly(vinylamine)/ SBA-15 as a novel heterogeneous hybrid catalyst. RSC Adv. 3 (31), 12816-12825. DOI: 10.1039/c3ra22579h.

28. Erdem, B., Erdem, S., Oksuzoglu, R.M. \& Citak, A. (2013). High-surface-area SBA-15-SO3H with enhanced catalytic activity by the addition of poly(ethylene glycol). J. Porous Mat. 20 (5), 1041-1049. DOI: 10.1007/s10934-013-9685-3.

29. Alavi, S., Hosseini-Monfared, H. \& Siczek, M. (2013). A new manganese(III) complex anchored onto SBA-15 as efficient catalyst for selective oxidation of cycloalkanes and cyclohexene with hydrogen peroxide. J. Mol. Catal. A: Chem. 377, 16-28. DOI: 10.1016/j.molcata.2013.04.013.

30. Ma, Z., Wang, X., Wei, S., Yang, H., Zhang, F., Wang, P. \& Ma, J. (2013). Cu (I) immobilized on functionalized SBA15: A recyclable catalyst for the synthesis of 1,3-diynes using terminal alkynes without base. Catal. Commun. 39, 24-29. DOI: 10.1016/j.catcom.2013.04.012.

31. Zhao, D., Huo, Q., Feng, J., Chmelka, B.F. \& Stucky, G. D. (1998). Nonionic Triblock and Star Diblock Copolymer and Oligomeric Surfactant Syntheses of Highly Ordered, Hydrothermally Stable, Mesoporous Silica Structures. J. Am. Chem. Soc. 120 (24), 6024-6036. DOI: 10.1021/ja974025i.

32. Wu, Z.Y., Wang, H.J., Zhuang, T.T., Sun, L.B., Wang, Y.M. \& Zhu, J.H. (2008). Multiple Functionalization of Mesoporous Silica in One-Pot: Direct Synthesis of Aluminum-Containing Plugged SBA-15 from Aqueous Nitrate Solutions. Adv. Funct. Mater. 18 (1), 82-94. DOI: 10.1002/adfm.200700706.

33. Yang, Y., Ding, H., Hao, S., Zhang, Y. \& Kan, Q. (2011). Iron(III), cobalt(II) and copper(II) complexes bearing 8-quinolinol encapsulated in zeolite-Y for the aerobic oxidation of styrene. Appl. Organometal. Chem. 25 (4), 262-269. DOI: 10.1002/aoc.1752.

34. Mahdavi, V. \& Mardani, M. (2012). Selective oxidation of benzyl alcohol with tert-butylhydroperoxide catalysed via Mn (II) 2, 2-bipyridine complexes immobilized over the mesoporous hexagonal molecular sieves (HMS). J. Chem. Sci. 124 (5), 1107-1115. DOI: 10.1007/s12039-012-0307-4. 